\title{
Anticancer Activity of Phenolic Acids of Natural or Synthetic Origin: A Structure-Activity Study
}

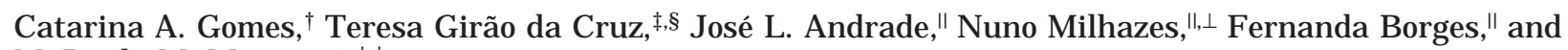 \\ M. Paula M. Marques*,t, \\ Research Unit "Molecular Physical-Chemistry", Biochemistry Department, and Centre for Neuroscience and Cellular Biology, \\ University Coimbra, 3001-401 Coimbra, Portugal, CE QOF FUP/ Organic Chemistry Department, Faculty of Pharmacy, \\ University Porto, 4050-047 Porto, Portugal, and Institute of Health Sciences-N orth, 4585-116, Gandra, Paredes, Portugal
}

Received J uly 10, 2003

\begin{abstract}
Several phenolic acids-caffeic and gallic acid derivatives-were synthesized and screened for their potential antiproliferative and cytotoxic properties, in different human cancer cell lines: mammary gland and cervix adenocarcinomas and lymphoblastic leukemia. The selected phenols were structurally related, which allowed us to gather important information regarding the structure-activity relationships underlying the biological activity of such compounds. This is proposed to be due to a balance between the antioxidant and pro-oxidant properties of this kind of agent. Distinct effects were found for different cell lines, which points to a significant specificity of action of the drugs tested. It was verified, for the types of cancer investigated, that the trihydroxylated derivatives yiel ded better results than the dihydroxylated ones. Tests in noncancerous cells, human lung fibroblasts, were also undertaken, in view of determining the toxic side effects of the compounds studied.
\end{abstract}

\section{Introduction}

Recent interest in food phenolics from diet, mainly from fruits and vegetables, has increased, owing to their role as antioxidants and their implication in the prevention of pathologies such as cancer, 1,2 cardiovascular diseases, ${ }^{3-6}$ and inflammatory disorders. ${ }^{7}$ Actually, this kind of compounds has been reported to display some relevant biological activities ${ }^{8-10}$ such as antibacterial, antiviral, immune-stimulating and estrogenic effects, ${ }^{9}$ and antiproliferative and cytotoxic properties in several tumor cells. ${ }^{8,11}$

The specific role of dietary or synthetic antioxidants in carcinogenesis has not been unequivocally elucidated. ${ }^{12}$ The main mechanism proposed for this protective action against deleterious oxidative processes is related to the free radical scavenging activity of the compounds, ${ }^{6}$ since reactive oxygen and nitrogen species are involved in several pathogenic processes. ${ }^{7}$ Antioxidants have been thought to mainly suppress carcinogenesis during the initiation phase, since most act as radical scavengers, inducers, or inhibitors of xenobiotics metabolizing enzymes, including phase I and II enzymes. On the other hand, several antioxidants that can inhibit the initiation events have been found to be second-stage tumor promoters. ${ }^{13}$

A possible, although insufficiently investigated, mechanism of polyphenol cytotoxicity may be related to their pro-oxidant properties, since the same polyphenols could behave as both antioxidant and pro-oxidant, depending on the concentration and free radical source. ${ }^{14}$

* To whom correspondence should be addressed. Tel/fax:+351-239826541. E-mail:pmc@ci.uc.pt. bra.

† Research Unit "Molecular Physical-Chemistry", University Coim-

‡ Biochemistry Department, University Coimbra.

$\S$ Centre for Neuroscience and Cellular Biology, University Coimbra.

" University Porto.

$\perp$ Institute of Health Sciences-North.
The ability of phenols to protect cells from oxidative stress has been demonstrated, $, 9,15$ but these compounds show a wide and contradictory behavior, involving antitumor and pro- and antimutagenic activity, depending on the specific system and conditions investigated. The antiproliferative effects (through apoptosis) induced by the phenolic agents on several cancer cell lines, for instance, were explained in terms of topoisomerase ${ }^{16}$ or phosphatidylinositol-3-kinase ${ }^{11}$ inhibition, or even cell cycle arrest. ${ }^{17}$ It is generally appreciated that the toxicity associated with some phenolic compounds is mediated by their oxidative activity, 18 which can accelerate oxidative damage in vitro, either to DNA or to proteins and carbohydrates. ${ }^{19}$ Another possible, although insufficiently investigated, mechanism of phenol cytotoxicity may be associated with their pro-oxidant properties. ${ }^{14}$ Depending on the structure, dose, target molecule, and environment, phenols may stimulate or inhibit the oxidative damage processes to biomolecules. ${ }^{20}$ Indeed, it is believed that they can behave as either antioxidants or pro-oxidants ${ }^{14,21}$ and that the inhibitory potency displayed on the growth and proliferation of certain malignant cells in vitro is strongly dependent on their structural characteristics. ${ }^{14,22,23}$

In the present study, several phenolic acid derivatives structurally related with the natural ones-varying in the number of $\mathrm{OH}$ ring substituents and in the length and/or degree of saturation of the carbon chain between the phenyl and the terminal carboxylate groups, which are known to exhibit antioxidant activity 19,24,25-were tested for their cytotoxic and cell growth inhibition properties in different human cancer cells, i.e., leukemia and epithelial-like adherent lines. Once this antitumor activity is prone to be strongly dependent on the conformational behavior of the drugs, this work was meant as an interactive study, the structural characteristics of the compounds investigated being deter- 

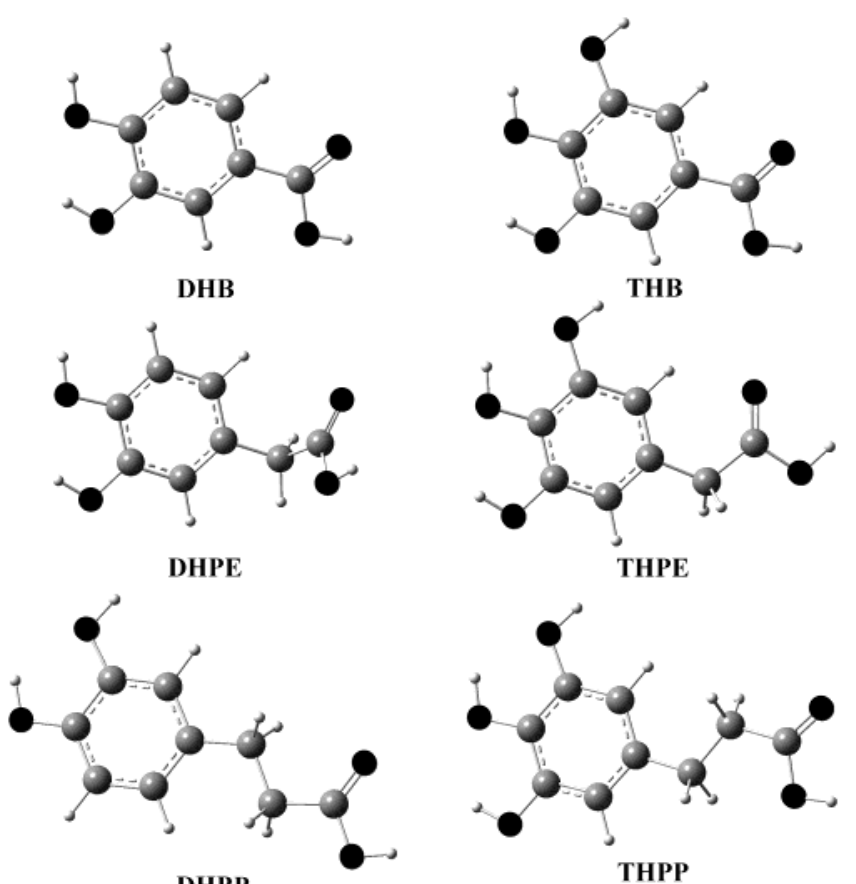

DHPP

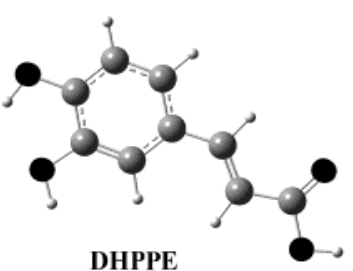

Figure 1. Schematic representation of the different phenolic acid derivatives studied in the present work (Calculated lowest energy geometries, yielded by ab initio DFT methods ${ }^{27,28}$ ).

mined through both vibrational spectroscopy and theoretical techniques and their synthesis being adapted according to the results of their cytotoxicity and antiproliferative evaluation. This follows a previous work, focusing on $\mathrm{Pt}(\mathrm{II})$ complexes of biogenic polyamines. ${ }^{26}$ Hopefully-in combination with spectroscopic (Raman and FTIR) and theoretical (ab initio) studies performed simultaneously on the same systems-a better understanding, at the molecular level, of the structureactivity relationships ruling the biochemical processes underlying the antitumor effect of this kind of compound may be achieved, which is vital in order to design new anticancer agents, with a higher (and perhaps selective) effect, as well as an optimized therapeutic efficacy (e.g. in cell lines displaying resistance to the clinically used compounds).

\section{Results and Discussion}

All the results presented were obtained by three independent methods: cell density measurement (Trypan blue exclusion method) and cellular viability assessment (MTT and Alamar blue colorimetric assays).

Seven phenolic acid derivatives were studied (Figure 1): four dihydroxylated ones (catechols), protocatechuic acid (3,4-dihydroxybenzoic acid, DHB), 3,4-dihydroxyphenyl ethanoic acid (DHPE), hydrocaffeic acid (3-(3,4dihydroxyphenyl)propanoic acid, DHPP), trans-caffeic acid (trans-3-(3,4-dihydroxyphenyl)-2-propenoic acid, DHPPE), and the three analogous trihydroxylated compounds, gallic acid (3,4,5-trihydroxybenzoic acid,
THB), 2-(3,4,5-trihydroxyphenyl)ethanoic acid (THPE) and 3-(3,4,5-trihydroxyphenyl)propanoic acid (THPP). These distinct phenols, to be assessed for their antitumor activity, differ mainly in the number of ring $\mathrm{OH}$ substituents and/or in the length and degree of saturation of the side chain between the ring and the terminal carboxylate group. To determine the effect of the conformational characteristics of this kind of compound in its cytotoxic and/or antiproliferative activity, the present study was developed. In fact, these structural differences were indeed found to lead to distinct values of cell density and/or viability in the presence of the agent tested, thus allowing the establishment of some structure-activity relationships ruling its biological function, as well as to ascertain the occurrence (or not) of specificity toward a particular type of cancer cell line.

The phenols under study were tested in three different human cancer cell lines: cervix ( $\mathrm{HeLa}$ ) and mammary gland (MDA-MB-231) adenocarcinomas and lymphoblastic leukemia (MOLT-3). It should be stressed that the chemotherapeutic drugs in clinical use show a significant disadvantage, which is related with its high toxicity toward healthy cells. To investigate the toxicological behavior of the compounds studied, experiments were carried out in nonneoplasic cells, fibroblasts from human embryonic lung tissue (L-132 cell line).

It was verified that an increase in the number of the $\mathrm{OH}$ ring substituents in the compounds investigated leads to higher antiprol iferative and cytotoxic activities, in all the cell lines tested (Figures 2 and 3). This effect is particularly pronounced for the MDA-MB-231 line, for which the dihydroxylated phenolic acids-mainly DHPE and DHPP-hardly showed any cytotoxic activity (Figure 2). The effect of a change in the length of the substituent chain was found to be variable and strongly dependent on the cell line, both for di- and triphenols (Figure 2). For trihydroxylated phenols, for instance, a regular increase of the cytotoxic effect was observed toward the leukemia line MOLT-3 as the chain length increased, as opposed to the other cells tested, either fibroblasts or cancer cells. Thus, an increase in the length of the carbon chain apparenty does not interfere with the effect of the number of $\mathrm{OH}$ substituents, which is clearly predominant. As to the effect of the degree of saturation of the carbon chain, it was observed, for all the cell lines tested, that the presence of a double bond is associated with an increase in cell viability as compared to the saturated compounds (Figure 4). According to published results, ${ }^{29}$ this may be partly due to the increased antioxidant ability of the unsaturated phenols, which seems to be associated with a protective effect of the cell integrity.

The results presently obtained evidence a selectivity of both the antiproliferative and cytotoxic activities of the phenolic acids studied against some of the cancer cell lines tested (Figure 5), which will be presently discussed.

3,4-Dihydroxybenzoic Acid (DHB). DHB displayed a reversible antiprol iferative effect toward all the cancer cells investigated, for a concentration equal to or higher than $50 \mu \mathrm{M}$, except for MDA-MB-231 (Figure 5). In fact, this was found to be the only cell line tested for which DHB had an irreversible cell-growth inhibition activity, 
DHB DHPE

A

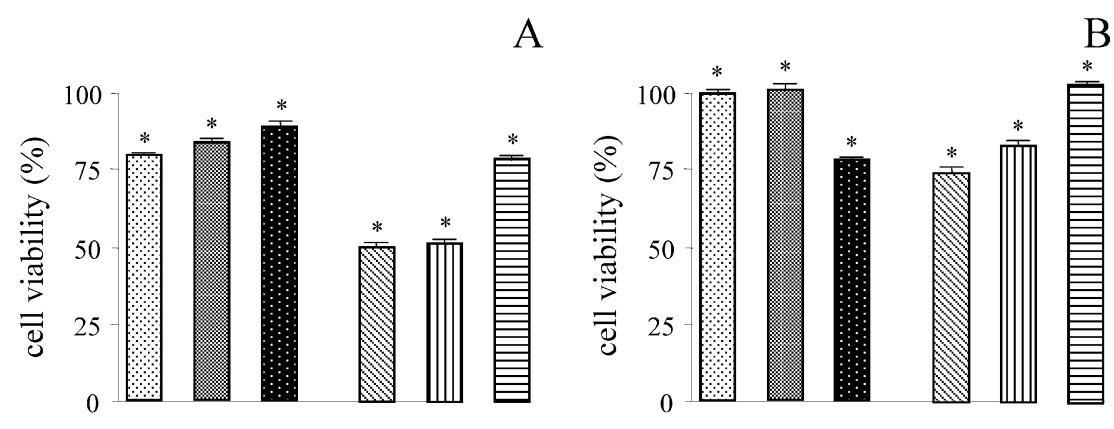

$\mathrm{C}$

$\mathrm{D}$
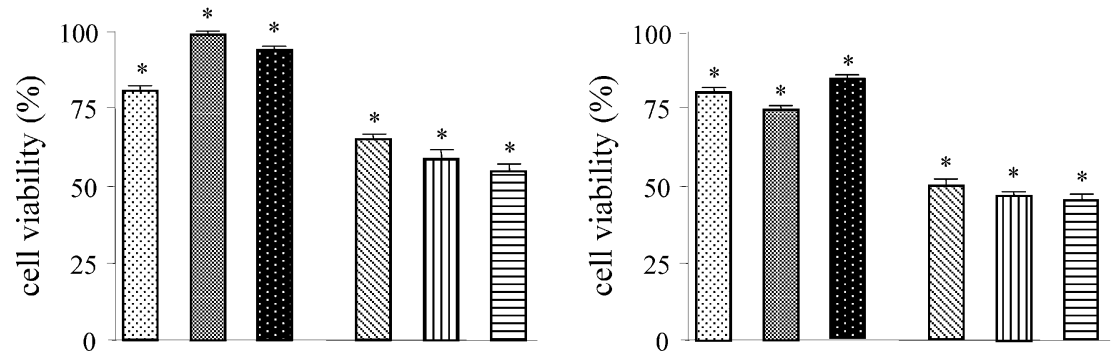

Figure 2. Plot of cell viability for dihydroxylated (DHB, DHPE and DHPP) and trihydroxylated (THB, THPE, and THPP) phenols $(100 \mu \mathrm{M})$, against L-132 (A), HeLa (B), MDA-MB-231 (C), and MOLT-3 (D) cell lines, after $72 \mathrm{~h}$ of incubation with the drug. The cell viability was determined by the MTT assay (as described in the Experimental Section). The data are expressed as a percentage of the control MTT reduction (always taken as 100\%) and represent the average \pm mean standard deviation from two independent experiments carried out in triplicate. Intergroup comparison: $* p<0.05$.

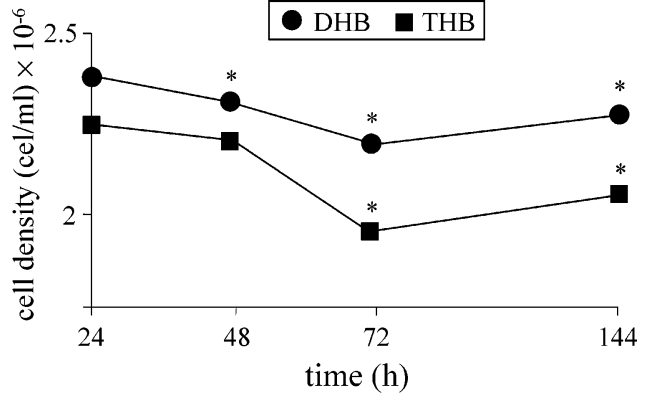

Figure 3. Antiproliferative effect of $\mathrm{DHB}$ and THB $(75 \mu \mathrm{M})$ toward MOLT-3 cells. The cell density was assessed by the Trypan blue exclusion method (as described in the Experimental Section). The results are the mean \pm standard deviation obtained in experiments performed in triplicate. (Cell density for the control: $24 \mathrm{~h}, 8.0 \times 10^{6} \mathrm{cells} / \mathrm{mL} ; 48 \mathrm{~h}, 17.0 \times$ $10^{6} \mathrm{cells} / \mathrm{mL} ; 72 \mathrm{~h}, 20.0 \times 10^{6} \mathrm{cells} / \mathrm{mL} ; 144 \mathrm{~h}, 25.0 \times 10^{6}$ cells/ $\mathrm{mL}$.) Intergroup comparison: $* \mathrm{p}<0.01$.

the cell viability being reduced by ca. $20 \%$ in the presence of this phenol (Figure 2).

3,4-Dihydroxyphenylethanoic Acid (DHPE). DHPE displayed a specific and almost irreversible antiproliferative and cytotoxic effects on MOLT-3 cells, with cell viability reduced to ca. $75 \%$ after $72 \mathrm{~h}$ of incubation (for concentrations equal to or higher than $50 \mu \mathrm{M})$. The viability of HeLa and MDA-MB-231 cells, in turn, is hardly affected by this phenolic acid (Figure 2). However, the MDA-MB-231 line showed a clear decrease in cell density even after removal of this phenol (Figure 5).

Hydrocaffeic Acid (DHPP). This phenolic acid was found to have an irreversible antiproliferative activity toward all the cell lines studied (including the L-132 fibroblasts) (Figure 5), along with a rather modest

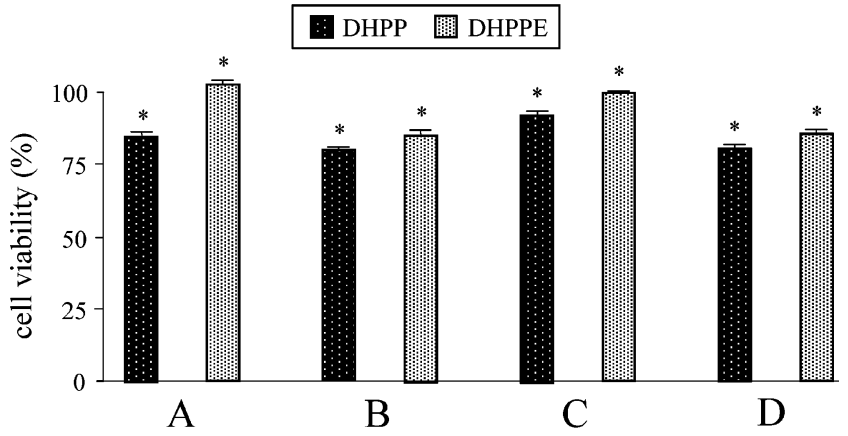

Figure 4. $P$ lot of cell viability for compounds DHPP and DHPPE (100 $\mu \mathrm{M})$, against L-132 (A), HeLa (B), MDA-MB-231 (C), and MOLT-3 (D) cell lines. The cell viability was determined by the MTT assay (as described in the Experimental Section), after $72 \mathrm{~h}$ of incubation with the drug. The data are expressed as a percentage of the control MTT reduction (always taken as $100 \%$ ), and represent the average \pm mean standard deviation from two independent experiments carried out in triplicate. Intergroup comparison: ${ }^{*} \mathrm{p}<0.05$.

cytotoxic effect (Figure 2). This compound displayed a clear specificity against the adenocarcinoma lines tested, mainly toward $\mathrm{HeLa}$, for which it induced a cell density decrease of $5 \times 10^{6}$ to $5 \times 10^{5} \mathrm{cell} / \mathrm{mL}$, after $72 \mathrm{~h}$ of incubation (Figure 5). With the exception of the fibroblasts, the cell-growth inhibition induced by DHPP continued to increase, even in the absence of the phenol (Figure 5), which is a significant advantage for its possible use as an anticancer drug.

trans-Caffeic Acid (DHPPE). Caffeic acid (DHPPE), a dihydroxylated phenol displaying an unsaturated carbon side chain, exhibited an antiproliferative effect against all the cell lines investigated (Figure 5), particularly toward HeLa (cell density is decreased ca. 

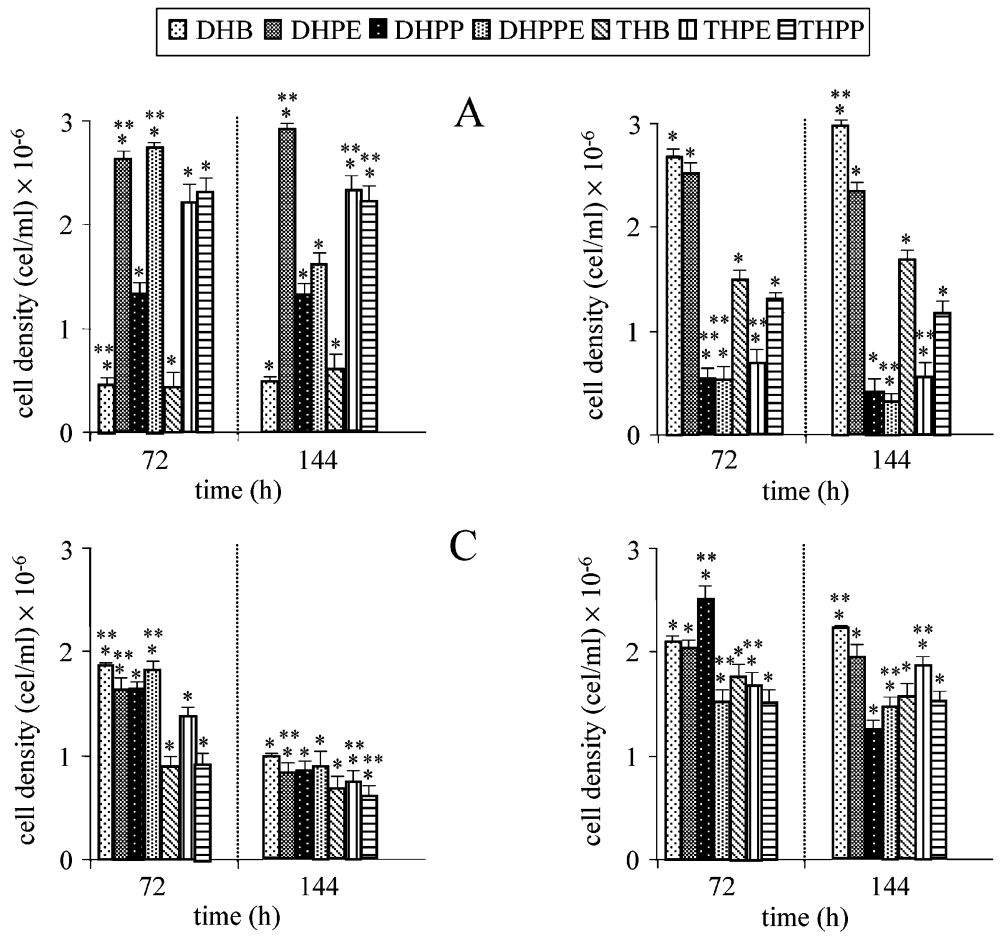

Figure 5. Antiproliferative effect of the phenolic acids studied (50 $\mu \mathrm{M})$, toward the L-132 (A), HeLa (B), MDA-MB-231, (C) and MOLT-3 (D) cell lines. The samples $\left(5 \times 10^{6}\right.$ cells $\left./ \mathrm{mL}\right)$ were incubated with the drugs for a period of $72 \mathrm{~h}$, after which aliquots of the cell suspensi ons were removed and cell viability was evaluated by the MTT colorimetric assay (as described in the Experimental Section). In addition, the drug was removed $72 \mathrm{~h}$ after seeding and the cell viability was assessed following a further incubation of $72 \mathrm{~h}$. The data are expressed as a percentage of the control MTT reduction (100\%) and represent the average \pm mean standard deviation from experiments carried out in triplicate. Intergroup comparison: between the different compounds, $* p<0.05$; between cell lines, ${ }^{* *} \mathrm{p}<0.01$. (Cell density for the control samples: $72 \mathrm{~h}, 18.0-20.0 \times 10^{6}$ cells $/ \mathrm{mL} ; 144 \mathrm{~h}, 25.0 \times 10^{6} \mathrm{cells} / \mathrm{mL}$.)

10-fold by $72 \mathrm{~h}$ incubation with this agent, Figure 5) and, to a lesser extent, MDA-MB-231. However, a very low, quite reversible, cytotoxic activity was detected for concentrations between 50 and $100 \mu \mathrm{M}$ (Figure 4).

Gallic Acid (THB). THB showed both antiproliferative and cytotoxic activity against all the cancer cells investigated: cell viabilility decreased to $74 \%, 65 \%$, and $50 \%$ for HeLa, MDA-MB-231, and MOLT-3, respectively, after $72 \mathrm{~h}$ of incubation with the phenol (Figures 2 and 5). This effect was found to be irreversible for both the MDA-MB-231 and MOLT-3 lines, cell viability being al most completely restored $72 \mathrm{~h}$ after drug removal for the HeLa and L-132 cells. THB showed itself to be a particularly effective anticancer agent toward the leukemia MOLT-3 cell line, which was found to be seriously, and irreversibly, damaged already after $48 \mathrm{~h}$ of drug exposure.

2-(3,4,5-Trihydroxyphenyl)ethanoic Acid (THPE). This compound was also found to display a quite high antiprol iferative and cytotoxic effect against all cancer cells investigated: viability decreased to $50 \%, 80 \%, 60 \%$, $47 \%$, at $72 \mathrm{~h}$ of incubation, for L-132, HeLa, MDA-MB231, and MOLT-3 lines, respectively (for a $100 \mu \mathrm{M}$ concentration, Figure 2). This antitumor activity was shown to be particularly pronounced for the HeLa cells, as not only was it not reversed by drug removal but both the cell density and viability decreased even further with time, in the absence of phenol (Figure 5). I ts effect on the MDA-MB-231 line was also irreversible, as opposed to the leukemia MOLT-3 cells, which reflects a preference of this phenolic compound for adenocarcinoma-type lines.
3-(3,4,5-Trihydroxyphenyl)propanoic Acid (THPP). The tryhydroxylated phenol THPP revealed a quite high antiproliferative and cytotoxic activity against both MDA-MB-231 and MOLT-3 cancer lines: viability decreased to ca. $55 \%$ and $45 \%$, respectively, already after $48 \mathrm{~h}$ of incubation with the compound (Figure 2). This activity was clearly sel ective toward the MDA-MB-231 carcinoma (Figures 2 and 5), the only cancer cells incubated with this phenol for which an irreversible effect was evaluated.

From the results presently obtained, one may conclude that the antiproliferative and cytotoxic effects of this kind of phenolic compounds are mainly ruled by their conformational preferences, which strongly determine their antioxidant and/or pro-oxidant activity. The latter plays a vital role in the mechanism through which the phenols exert their anticancer action and depends on the number of ring substituent hydroxyl groups, as well as (to a smaller extent) on the length and degree of saturation of the carbon chain within the molecule. In fact, this kind of phenolic acid appears to be highly reactive insi de the cell, ${ }^{30}$ and an accurate evaluation of the exact amount of agent necessary to reach a certain tissue, enter the cell wall, and perform an effective tumor inhibitory function (without affecting significantly the normal cell function) will require further study.

From the cell viability plots and dose-response curves-cell density and/or viability variation as a function of both the incubation time and drug concentration obtained for the distinct phenols and cell lines studied-it is possible to draw the following conclusions 
on the potential anticancer properties of those phenolic acids: (i) The number of $\mathrm{OH}$ ring substituents seems to be the most determinant factor; triphenols were found to be more effectivethan diphenols for all types of cancer lines investigated (Figures 2, 3, and 5). (ii) The length of the carbon chain between the aromatic ring and the terminal carboxylic group affects the anticancer activity differently according to each phenolic acid and each particular cell line, the response strongly suggesting a specificity of action toward certain cancer types ( $F$ igure 5). (iii) The presence of a double bond in the carbon chain, a structural feature that remains controversial in its relation to the antioxidant activity, ${ }^{31}$ was not found to behave accordingly in all cell lines tested along this work. Actually, by comparing the antitumor effect of compounds DHPP and DHPPE, the increase in viability (Figure 4) (and, in most cases, in cell density, Figure 5) due to the presence of this double bond (in DHPPE) is clearly evidenced. (iv) Some of the phenolic acids studied were found to display a protective effect toward certain cell lines, either cancerous or healthy ones, i.e., THPP toward HeLa (Figure 2), and DHPPE toward L-132 (Figure 4). (v) The experiments performed in noncancerous cells allowed us to conclude that, in general, these kinds of compounds do not display a significant toxicity toward healthy cells, as their effect, both on cell density and viability, was found, in most cases, to be highly reversible.

The cytotoxic and growth-inhibition effect of the phenols tested (particularly THPP) on the mammary gland adenocarcinoma MDA-MB-231 line was determined to be significant and in most cases irreversible. Also, from the three different cancer cells investigated, the leukemia MOLT-3 line was shown to be the most sensitive line to the natural and synthetic phenolic acids presently studied (mainly to THB).

\section{Summary and Conclusions}

The time and dose-dependent antiproliferative and cytotoxic effects of distinct di- and trihydroxylated phenolic acids-DHB, DHPE, DHPP, DHPPE, THB, THPE, and THPP-against the human adenocarcinoma and leukemia cell lines HeLa, MDA-MB-231, and MOLT-3 was assessed, as was their toxicity toward healthy cells (L-132 human fibroblasts). The results obtained allowed us to ascertain some important structure-activity relationships ruling the antitumor activity of such compounds, which is determined by their antioxidant and/or pro-oxidant properties (depending on their concentration and on the surrounding conditions).

Trihydroxylated derivatives were found to display a greater cytotoxicity, as well as antiproliferative effect, as compared to the dihydroxylated ones. Preliminary studies on the radical scavenging activity of dihydroxyand trihydroxyphenolic acids show that the later ones reveal remarkably higher activities. ${ }^{31-33}$ On the other hand, the presence of a double bond in the side chains was found to lead to an increase of those activities. The length and degree of saturation of that pendant arm, however, does not induce a typical profile, the response being strongly dependent on the cell type.

Some of the phenols studied al ong this work reveal ed themselves as quite efficient antiproliferative and cytotoxic agents against some types of human cancer cells, namely, DHPP, DHPPE, and THPE toward HeLa cervix adenocarcinoma; THPP against MDA-MB-231 breast cancer; and THB on MOLT-3 leukemia line. These compounds did not reveal a significant toxicity toward healthy cells, as their antiproliferative and/or cytotoxic effect toward these, when present, were completely reversed upon drug removal.

From the results gathered it is possible to conclude that the antitumor activity of these compounds is highly dependent upon their conformational characteristics, which, in turn, determine their antioxidant/pro-oxidant properties. Consequently, the design of new, more effective anticancer drugs should be ruled by these crucial factors, as slight changes in either the number of ring $\mathrm{OH}$ substituents or the length and degree of saturation of the carbon chain between the ring and the carboxylate group are enough to significantly modify the in vitro antiproliferative and cytotoxic properties of phenolic acids. F urthermore, cell line specificity and low toxicity toward noncancerous cells are also goals to be hopefully achieved in the near future.

\section{Experimental Section}

Chemicals. Culture media (DMEM-HG and RPMI-1640), antibiotics (penicillin-streptomycin 100x solution), transcaffeic acid (trans-3-(3,4-dihydroxyphenyl)-2-propenoic acid, 3,4-dihydroxycinnamic acid), hydrocaffeic acid (3-(3,4-dihydroxyphenyl)propanoic acid, 3-(3,4-dihydroxy)hydrocinnamic acid), 3,4-dihydroxyphenylethanoic acid, protocatechuic acid (3,4-dihydroxybenzoic acid), gallic acid (3,4,5-trihydroxybenzoic acid), 2-(3,4,5-trimethoxyphenyl)ethanoic acid, 3-(3,4,5-trimethoxyphenyl)propanoic acid, antibiotics, culture media, cisplatin (cis-Pt $\left(\mathrm{NH}_{3}\right)_{2} \mathrm{Cl}_{2}$ ), dimethyl sulfoxide- $\mathrm{d}_{6}$, glucose, glutamine, HEPES, MTT, phenol red (phenolsulfonphthalein), tetramethylsilane $\left(\mathrm{Si}\left(\mathrm{CH}_{3}\right)_{4}\right)$, trypan blue $(0.4 \%$ solution, pre pared in $0.81 \%$ sodium chloride and $0.06 \%$ dibasic potassium phosphate), inorganic salts, and acids (of analytical grade) were obtained from Sigma-Aldrich Chemical Co. (Sintra, Portugal). Silica gel 60 F254 and $60(0.2-0.5 \mathrm{~mm})$ was purchased from E. Merck (Lisbon, Portugal). Fetal calf serum was obtained from Biochrom KG, Berlin. Alamar blue was purchased from Accurate Chemical \& Scientific Corp., Westbury, New York. All other reagents and solvents (pro analysis grade) were purchased from Merck (Lisbon, Portugal).

Cells. The foll owing human cell lines were used: E pitheliallike adherent cell lines from human cervix adenocarcinoma (HeLa) and from mammary gl and adenocarcinoma (MDA-MB231), acutelymphoblastic leukemia (MOLT-3), and fibroblasts from embryonic lung tissue (L-132). HeLa was purchased from the European Collection of Cell Cultures (ECACC). MDA-MB231 was obtained from the American Type Culture Col lection (ATCC). MOLT-3 was made available by the Biochemistry Service of the F aculty of Medicine of the University of Coimbra, while the L-132 cell line was kindly offered by the Centre of Experimental Medicine and Surgery of the University General Hospital Gregorio Marañon (Madrid, Spain).

Physical Measurements. Synthesized compounds were identified by FTIR, UV, NMR, and EI-MS. Infrared spectra were recorded on an ATI Mattson Genesis Series FTIR spectrometer, using potassium bromide disks. Only the most significant absorption bands are reported $\left(v_{\max }, \mathrm{cm}^{-1}\right) .{ }^{1} \mathrm{H}$ and ${ }^{13} \mathrm{C}$ NMR data were acquired, at room temperature, on a Brüker AMX 300 spectrometer, operating at 300.13 and 75.47 $\mathrm{MHz}$, respectively. Dimethyl sulfoxide- $\mathrm{d}_{6}$ was used as a solvent; chemical shifts are expressed in $\delta(\mathrm{ppm})$ values relative to tetramethylsilane (TMS) as internal reference; coupling constants $(J)$ are given in hertz. Assignments were also made from DEPT (distortionless enhancement by polarization transfer) (underlined values). Electron impact mass spectra (EI-MS) were carried out on a VG AutoSpec instrument; the data are reported as $\mathrm{m} / \mathrm{z}$ (\% of relative intensity of 
the most important fragments). Melting points were obtained on a Köfler microscope (Reichert Thermovar) and are uncorrected. Thin-layer chromatography (TLC) was carried out on precoated silica gel 60 F 254 with the layer thickness of 0.2 $\mathrm{mm}$.

Synthesis. 2-(3,4,5-Trihydroxyphenyl)ethanoic Acid (THPE ). A solution of 2-(3,4,5-trimethoxyphenyl)ethanoic acid ( $3.0 \mathrm{~g})$ and acetic acid $(8 \mathrm{~mL})$ in concentrated hydrobromic acid $(10 \mathrm{~mL}$ ) was refluxed for $15 \mathrm{~h}$ until the starting material was no longer detected by TLC. A saturated solution of sodium sulfate $(25 \mathrm{~mL})$ was added to the reaction mixture and then extracted with diethyl ether. The organic layers were combined, washed twice with water, and dried over anhydrous magnesium sulfate, and the solvent was evaporated under reduced pressure. The crude product was purified on silica gel column using diethyl ether/petroleum benzine. The acid was recrystallized from acetone/chloroform to yield 31\% of light pink crystals; The following systems were used for analytical control: silica gel, petroleum benzine/diethyl ether/formic acid (5:5:0.1); silica gel, chloroform/methanol/formic acid (9:1:0.5). The spots were visualized under UV detection (254 and 366 $\mathrm{nm})$ and iodine vapor and $\mathrm{FeCl}_{3} . \mathrm{FTIR} v_{\max }\left(\mathrm{cm}^{-1}\right)(\mathrm{KBr}) 3399$, $3352,3254,2926,2727,2048,1804,1705,1634,1613,1539$, $1467,1424,1389,1310,1254,1237,1200,1179,1144,1035$, $999,932,905,838,824,801,721,652,620 ;{ }^{1} \mathrm{H}$ NMR $\delta 3.23$ $\left(2 \mathrm{H}, \mathrm{s} ; \mathrm{CH}_{2}\right), 6.14(2 \mathrm{H}, \mathrm{s} ; \mathrm{H}(2,6)), 7.94(1 \mathrm{H}, \mathrm{s} ; \mathrm{OH}(4)), 8.75(2 \mathrm{H}$, s; $\mathrm{OH}(3,5)), 12.12(1 \mathrm{H}, \mathrm{s} ; \mathrm{COOH}) ;{ }^{13} \mathrm{C} \mathrm{NMR} \delta 40.6 \mathrm{CH}_{2}, 108.0$ $\mathrm{C}(2,6), 124.8 \mathrm{C}(1), 131.7 \mathrm{C}(4), 145.9 \mathrm{C}(3,5), 173.1 \mathrm{COOH}$; EI-MS m/z (\%) (M+•, 60), 139 (100), 65 (7), 53 (16); mp 147$150{ }^{\circ} \mathrm{C}$

3-(3,4,5-Trihydroxyphenyl)propanoic Acid (THPP). This compound was synthesized in a similar manner as $2-(3,4,5-$ trihydroxyphenyl)ethanoic acid, using 3-(3,4,5-trimethoxyphenyl)propanoic acid as reagent. The product was crystallized from ethanol//chloroform/petroleum benzine, yielding light gray crystals (26\%); FTIR $v_{\max }\left(\mathrm{cm}^{-1}\right)(\mathrm{KBr}) 3496,3437,3364$ $2958,2686,1834,1700,1632,1616,1550,1449,1417,1373$, $1348,1328,1278,1242,1204,1177,1145,1066,1005,981,934$, $852,832,796,767,729,688,615 ;{ }^{1} \mathrm{H}$ NMR $\delta 2.38(2 \mathrm{H}, \mathrm{t}, \mathrm{J}=$ 7.4; $\left.\mathrm{CH}_{2}(\alpha)\right), 2.55\left(2 \mathrm{H}, \mathrm{t}, \mathrm{J}=7.4 ; \mathrm{CH}_{2}(\beta)\right), 6.08(2 \mathrm{H}, \mathrm{s} ; \mathrm{H}(2,6))$, $7.85(1 \mathrm{H}, \mathrm{s} ; \mathrm{OH}(4)), 8.66(2 \mathrm{H}, \mathrm{s} ; \mathrm{OH}(3,5)), 12.05(1 \mathrm{H}, \mathrm{s}, \mathrm{COOH})$; ${ }^{13} \mathrm{C} \mathrm{NMR} \delta 30.1 \mathrm{CH}_{2}(\alpha), 35.7 \mathrm{CH}_{2}(\beta), 106.9 \mathrm{C}(2,6), 131.0 \mathrm{C}(1) *$, $131.1 \mathrm{C}(4) *, 146.0 \mathrm{C}(3,5), 174.0 \mathrm{COOH}$ (*These values can be interchanged); EI-MS m/z (\%) $198\left(\mathrm{M}^{+} \cdot, 61\right), 153(22), 139(100)$, 135 (7), 123(9), 107 (9), 77 (9), 65 (7), 53 (14); mp 142-144 ${ }^{\circ} \mathrm{C}$.

Preparation of Solutions. All compounds studied are water-soluble in the concentration range used, from $1.0 \times 10^{-5}$ to $1.0 \times 10^{-4} \mathrm{M}$. Solutions were prepared in phosphatebuffered saline solution (PBS): $132.0 \times 10^{-3} \mathrm{M} \mathrm{NaCl}, 4.0 \times$ $10^{-3} \mathrm{M} \mathrm{KCl}, 1.2 \times 10^{-3} \mathrm{M} \mathrm{NaH}_{2} \mathrm{PO}_{4}, 1.4 \times 10^{-3} \mathrm{M} \mathrm{MgCl}_{2}, 6.0$ $\times 10^{-3} \mathrm{M}$ glucose, $1.0 \times 10^{-2} \mathrm{M}$ HEPES ( $\mathrm{N}$-(2-hydroxyethyl)piperazine-N'-[4-butanesulfonic acid]). Fresh solutions were prepared monthly and kept from light, to prevent oxidation. Trypan blue was used as a $0.04 \%$ (w/v) solution in PBS. MTT (3-(4,5-dimethylthiazol-2-yl)-2,5-diphenyltetrazolium bromide) was prepared, in a concentration of $0.5 \mathrm{mg} / \mathrm{mL}$, in PBS solution containing $1.0 \times 10^{-3} \mathrm{M} \mathrm{CaCl}_{2}$.

Biological Assays. Cell Culture. Stock cultures of cells were maintained at $37{ }^{\circ} \mathrm{C}$, under $5 \% \mathrm{CO}_{2}$. HeLa, MDA-MB231, and L-132 (grown in monolayers) were kept in Dulbecco's modified Eagle's high glucose $(4500 \mathrm{mg} / \mathrm{L})$ medium (DMEMHG), supplemented with $10 \%$ heat-inactivated fetal calf serum, glutamine (1.168 $\mathrm{g} / \mathrm{L})$, and antibiotics (100 units of penicillin and $100 \mathrm{mg}$ of streptomycin). MOLT-3 was cultured as a suspension in Roswell Park Memorial Institute medium (RPMI-1640), containing 25 mM HEPES and 25 mM sodium bicarbonate, supplemented with $10 \%$ heat-inactivated fetal calf serum, glutamine $(0.3 \mathrm{~g} / \mathrm{L})$, and antibiotics (100 units of penicillin and $100 \mathrm{mg}$ of streptomycin). The cell lines were subcultured twice a week. All cells were harvested using a dissociation medium composed of $136.9 \times 10^{-3} \mathrm{M} \mathrm{NaCl}, 2.7 \times$ $10^{-3} \mathrm{M} \mathrm{KCl}, 8.2 \times 10^{-3} \mathrm{M} \mathrm{Na}_{2} \mathrm{HPO}_{4}, 1.5 \times 10^{-3} \mathrm{M} \mathrm{KH}_{2} \mathrm{PO}_{4}$, $4.0 \times 10^{-4} \mathrm{M}$ EDTA (ethylenediaminetetraacetic acid, di- sodium salt, dihydrate) ( $\mathrm{pH} 7.4)$ and containing $0.0004 \%$ (w/v) phenol red.

Toxicity and Cell Growth Inhibition Evaluation. Cytotoxicity and cell density evaluation after drug exposure, for drug concentrations between 5 and $100 \mu \mathrm{M}$, was assessed with use of standard assays. Cells were plated at $5 \times 10^{6} \mathrm{cell} / \mathrm{s} / \mathrm{mL}$ on 12-well dishes. Twenty-four hours after seeding, drug solutions were added to the medium and the cultures were incubated at $37^{\circ} \mathrm{C}$. Cells were harvested and analyzed (both in controls and in drug-treated cultures) every $24 \mathrm{~h}$, for a total period of 3-5 days (depending on the cell line and the compound used). Reversibility of the drug effect was tested by removing the drug and adding fresh culture medium in the last day of incubation with the drug and assessing the cell viability following three more days of incubation. Cell density and viability were determined by Trypan blue exclusion on single-cell suspensions obtained from the monolayer cultures. Cell viability was further assessed by both mitochondrial dehydrogenase activity (MTT assay ${ }^{34-37}$ ) and the Alamar blue col orimetric test. ${ }^{38,39}$ Measurements were carried out each 24 $\mathrm{h}$ and the results expressed as a percentage of the control (nontreated) cells, which was always taken as $100 \%$. All experiments were performed in triplicate.

The $50 \%$ inhibitory concentration $\left(\mathrm{IC}_{50}\right.$, concentration of drug required to inhibit cell growth by $50 \%$ ) was calculated, for each drug tested, from dose-response curves (for an incubation period of $72 \mathrm{~h}$ ).

Statistical Analysis. All experiments were performed in triplicate. The results are expressed as mean values \pm SD (the corresponding error bars being displayed in the graphical plots). Statistical analysis was performed using ANOVA, followed by post hoc test of Fisher's protected least significant difference. Statistical comparison between the data was based on the Pearson correlation coefficient, values less than 0.05 being considered as significant.

Acknowledgment. F.B., N.M. and J L.A. acknowledge the Portuguese FCT (I\&D No. 226/94), Project POCTI/QCA III (co-financed by FEDER), and PhD grant (PRAXIS XXI/BD//18520/98). The authors also wish to thank the Centre of Experimental Medicine and Surgery of the University General Hospital Gregorio Marañon, Madrid, Spain (in the person of Dr. Maria Concepción Guisasola Zululeta), for their kind offer of the L-132 cell line.

\section{References}

(1) Gao, T.; Ci, Y.; J ian, H.; An, C. FTIR Investigation of the Interaction of Tumour Cells Treated with Caffeic and Chlorogenic Acid. Vib. Spec. 2000, 24, 225-231, and refs. therein.

(2) Silva, A. M. S.; Santos, C. M. M.; Cavaleiro, J. A. S.; Tavares, H. R.; Borges, F.; Silva, F. A. M. NMR Studies on the Antiradical Mechanism of Phenolic Compounds Towards 2,2-Diphenyl-1picrylhydrazyl Radical. Magnetic Resonancein Food Science-A View to the Next Century; Royal Society of Chemistry: London, United Kingdom, 2001.

(3) Lubal, P.; Siroky, D.; Fetsch, D.; Havel, J. The Acidobasic and Complexation Properties of Humic Acids. Talanta 1998, 47, 401-412.

(4) Kordel, W.; Dassenakis, M.; Lintelmann, J .; Padberg, S. The Importance of Natural Organic Material for Environmental Processes in Waters and Soils. PureAppl. Chem. 1997, 69, 15711600.

(5) Bravo, L. Polyphenols: Chemistry, Dietary Sources, Metabolism and Nutritional Significance. Nutrition Rev. 1998, 56, 317-333.

(6) González, M. J .; López, D.; Argülies, M.; Riordan, N. H. Antioxidants and Prooxidants: A Commentary About their Apparent Discrepant Role in Carcinogenesis. Age 1996, 19, 17-18.

(7) I noue, M.; Sakaguchi, N.; I suzugawa, K.; Tani, H.; Ogihara, Y. Role of Reactive Oxygen Species in Gallic Acid-I nduce Apoptosis Biol. Pharm. Bull. 2000, 23, 1153-1157.

(8) Rapta, P.; Misík, V.; Stasko, A.; Vrábel, I. Redox I ntermediates of Flavonoids and Caffeic Acid Esters from Propolis: An EPR Spectroscopy and Cyclic Voltammetry Study. Free Rad. Biol Med. 1995, 18, 901-908.

(9) Rice-Evans, C. A.; Miller, N. J .; Paganga, G. Structure-antioxidant Activity Relationships of Flavonoids and Phenolic Acids. Free Rad. Biol Med. 1996, 20, 933-956. 
(10) Rajan, P.; Vedernikova, I.; Cos, P. B.; Dirk, V.; Augustyns, K.; Haemers, A. Synthesis and Evaluation of Caffeic Acid Amides as Antioxidants. Bioorg. Med. Chem. Lett. 2001, 11, 215-217.

(11) Agullo, G.; Gamet-Payrastre, L.; Manenti, S.; Viala, C.; Rémésy, C.; Chap, H.; Payrastre, B. Relationship Between Flavonoid Structure and Inhibition of Phosphatidylinositol-3-kinase and Protein Kinase C I nhibiton. Biochem. Pharmacol. 1997, 53, 6491657

(12) Aruoma, O. I. Nutrition and Health Aspects of Free Radicals and Antioxidants. Chem. Toxic. 1994, 32, 671-683.

(13) Nakamura, Y.; Torikai, K.; Ohto, Y.; Murakami, A.; Tanaka, T. Ohigashi, H. A Simple Phenolic Antioxidant Protocatechuic Acid Enhances Tumour Promotion and Oxidative Stress in $\mathrm{Fe}$ malenICR Mouse Skin: Dose- and Timing-Dependent Enhancement and Involvement of Bioactivation by Tyrosinase. Carcinogenesis 2000, 21, 1899-1907.

(14) Sergediene, E.; J onsson, K.; Szymusiak, H.; Tyrakowska, B. Rietjens, I. C. M.; Cenas, N. Prooxidant Toxicity of Polyphenolic Antioxidants to HL-60 Cells: Description of Quantitative Structure-Activity Relationships. FEBS Lett. 1999, 462, 392-396.

(15) Phan, T.-T.; Wang, L.; Grayer, R. J .; Chan, S.-Y.; Lee, S. T. Phenolic Compounds of Chromolaena Odorata Protect Cultured Skin Cells from Oxidative Damage: I mplication for Cutaneous Wound Healing. Biol. Pharm. Bull. 2001, 24, 1373-1379.

(16) Skaper, S. D.; Fabris, M.; Ferrari, V.; Carbonare, M. D.; Leon, A. Quercetin Protects Cutaneous Tissue-associated Cell Types Including Sensory Neurons from Oxidative Stress I nduced by Glutathione Depletion: Cooperative Effects of Ascorbic Acid. Free Rad. Biol Med. 1997, 22, 669-678.

(17) Lepley, D. M.; Li, B.; Birt, D. F.; Pelling, J . C. The Chemopre ventive Flavonoid Apigenin Induces G2/M Arrest in Keratinocytes. Carcinogenesis 1996, 17, 2367-2375.

(18) Li, Y.; Trush, M. Reactive Oxygen-Dependent DNA Damage Resulting from the Oxidation of Phenolic Compounds by a Copper-Redox Cycle Mechanism. Cancer Res. 1994, Supl. 54 1895-1898.

(19) Aruoma, O.; Murcia, A.; Butler, J .; Halliwell, B. Evaluation of Antioxidant and Prooxidant Actions of Gallic Acid and Its Derivatives. J . Agric. Food Chem. 1993, 41, 1880-1885.

(20) Khan, N. S.; Ahmad, A.; Hadi, S. M. Antioxidant, Prooxidant Properties of Tannic Acid and Its Binding to DNA. ChemicoBiol. Interac. 2000, 125, 177-189.

(21) Cao, G.; Sofic, E.; Prior, R. L. Antioxidant and Prooxidant Behaviour of Flavonoids: Structure-Activity Relationships. Free Rad. Biol Med. 1997, 22, 749-760.

(22) Castellucio, C.; Paganga, G.; Melikian, N.; Bolwell, G. P.; Pridham, J .; Sampson, J .; Rice, E. C. Antioxidant Potential of Intermediates in Phenylpropanoid Metabolism in Higher Plants. FEBS Lett. 1995, 368, 188-192.

(23) Passi, S.; Picardo, M.; Nazarro-Porro, M. Comparative Cytotoxicity of Phenols in vitro. Biochem. J . 1987, 245, 537-542.

(24) Masaki, H.; Okamoto, N.; Sakaki, S.; Sakurai, H. Protective Effects of Hydroxybenzoic Acids and their Esters on Cell Damage Induced by Hydroxyl Radicals and Hydrogen Peroxides. Biol. Pharm. Bull. 1997, 20, 304-308.
(25) Nakamura, Y.; Ohto, Y.; Murakami, A.; Ohigashi, H. Superoxide Scavenging Activity of Rosmarinic Acid from Perilla frutescens Britton Var. acuta f. viridis. J. Agric. Food Chem. 1998, 46, 4545-4550

(26) Marques, M. P. M.; Girão, T.; Pedroso de Lima, M. C.; Gameiro, A.; Pereira, E.; Garcia, P. Cytotoxic Effects of Metal Complexes of Biogenic Polyamines. I-Platinum (II) Spermidine Compounds: Prediction of their Antitumour Activity. Biochim Biophys. Acta-MCR 2002, 1589, 63-70.

(27) Van Besien, E.; Marques, M. P. M.J . Mol. Struct. (THEOCHEM) 2003, 625, 265-275.

(28) Marques, M. P. M.; et al. Unpublished results

29) Rice-Evans, C. A.; Miller, N. J : Paganga, G. StructureAntioxidant Activity Relationships of Flavonoids and Phenolic Acids. Free Rad. Biol Med. 1996, 20, 933-956.

(30) Newmark, H. L. Plant Phenolic Compounds as Inhibitors of Mutagenesis and Carcinogenesis. In Phenolic Compounds in Food and their Effects on Health II, Huang, M. T., Ho, C. T. Lee, C., Eds.; Oxford University Press (UK), 1996, Vol II, Chapter 4.

(31) Silva, F. A. M.; Borges, F.; Guimarães, C.; Lima, J . L. F. C.; Matos, C.; Reis, S. Phenolic Acids and Derivatives: Studies on the Relationship Among Structure, Radical Scaven ging Activity and Physicochemical Parameters. J. Agric. Food Chem. 2000, 48, 2122-2126.

(32) Paiva-Martins, F.; Milhazes, N.; Andrade, J. L.; Borges, F. Radical Scavenging Activity of Dihydroxy- and Trihydroxyphenolic Acids. Oxidants and Antioxidants in Biology-Book of Abstracts, 2003; p 169

(33) Salucci, M.; Stivala, L. A.; Maiani, G.; Bugianesi, R.; Vannini, V. Flavonoids Uptake and their Effect on Cell Cycle of Human Colon Adenocarcinoma Cells (Caco2). Br. J . Cancer 2002, 86, 1645-1651.

(34) Slater, T. F.; Sawyer, B.; Strauli, U. D. Studies on Succinate Tetrazolium reductase Systems. III-Points of Coupling of F our Different Tetrazolium Salts. Biochim. Biophys. Acta 1963, 77, 383-393.

(35) Mosmann, T. Rapid Colorimetric Assay for Cellular Growth and Survival: Application to Proliferation and Cytotoxicity Assays. J. I mmunol. Methods 1983, 65, 55.

(36) Ramanathan, R.; Das, N.P.; Tan, C. H. Effects of $\gamma$-Linolenic Acid, Flavonoids, and Vitamins on Cytotoxicity and Lipid Peroxidation. Free Rad. Biol Med. 1994, 16, 43-48.

(37) Rao, C. V.; Rivenson, A.; Simi, B.; Reddy, B. S. Chemoprevention of Colon Carcinigenesis by Dietary Curcumin, a Naturally Occurring Plant Phenolic Compound. Cancer Res. 1995, 55, 259266.

(38) Page, B.; Page, M.; Noel, C. A New Fluorimetric Assay for Cytotoxicity Measurements in vitro. Int. J . Oncology 1993, 3, 473-476.

(39) Nakayama, G. R.; Caton, M. C.; Nova, M. P.; Parandoosh, Z. Assessment of Alamar Blue Assay for Cellular Growth and Viability in vitro. J . Immunol. Methods 1997, 204, 205-208.

J M030956V 